\title{
An investigation into the depth and time dependent behavior of UV cured 3D ink jet printed objects - CORRIGENDUM
}

\author{
X. Chen, I.A. Ashcroft, C.J. Tuck, Y.F. He, R.J.M. Hague, and R.D. Wildman \\ doi: 10.1557/jmr.2017.4, Published by Materials Research Society with Cambridge University \\ Press, 20 February 2017
}

\begin{abstract}
After publication, Chen et al. ${ }^{1}$ requested an update to their Acknowledgments section to recognize additional information:

This work was supported by the Engineering and Physical Sciences Research Council [grant number EP/I033335/2], the support of University of Nottingham, and the Faculty of Engineering.
\end{abstract}

\section{REFERENCE}

1. X. Chen, I.A. Ashcroft, C.J. Tuck, Y.F. He, R.J.M. Hague, and R.D. Wildman: An investigation into the depth and time dependent behavior of UV cured 3D ink jet printed objects. J Mater. Res. 32(8), 1407-1420 (2017). doi: 10.1557/jmr.2017.4 